\title{
PESQUISA COM PROFISSIONAIS DA EDUCAÇÃO BÁSICA E POLÍTICAS PÚBLICAS DE FORMAÇÃO CONTINUADA: DIÁLOGOS PERTINENTES?
}

\author{
Gercina Santana Novais ${ }^{1}$ \\ Silma do Carmo Nunes ${ }^{2}$ \\ Andréa Porto Ribeiro ${ }^{3}$ \\ Cleber Ferreira Oliveira ${ }^{4}$
}

\section{Resumo}

Este texto aborda a adoção da pesquisa qualitativa como Política Pública de Formação Continuada e eixo estruturante das ações, apresentação e análise de resultados de pesquisa com profissionais da educação básica, inspirada na pesquisa-ação (THIOLLENT, 2009), utilizando-se das Rodas de Conversa (NASCIMENTO; SILVA, 2009) como espaço de produção e análise de dados, diálogos e elaboração de ações coletivas. Os resultados evidenciaram a importância da pesquisa no processo de formação continuada, na identificação, esclarecimento dos problemas, elaboração de ações coletivas e definição de políticas públicas educacionais. Demonstraram a necessidade de garantir tempo e espaços para a realização da pesquisa como eixo da formação contínua de profissionais da educação, reduzindo o distanciamento entre tradicionais formuladores de políticas públicas educacionais e esses profissionais.

Palavras-chave: Pesquisa; Formação Continuada; Rodas de Conversa; Instrumento de Elaboração de Políticas Públicas.

\footnotetext{
${ }^{1}$ Doutora em Educação pela Universidade de São Paulo -USP. Professora Colaboradora do Programa de PósGraduação em Educação da Universidade Federal de Uberlândia. Secretária de Educação no período de 2013 a 2016. E-mail: Gercinanovais@yahoo.com.br

2 Doutora em Educação pela Faculdade de Educação da Universidade Estadual de Campinas - UNICAMP. Diretora Acadêmica da Faculdade de Educação e Estudos Sociais de Uberlândia, mantida pela Fundação Presidente Antonio Carlos - FEESU/FUPAC. E-mail: leosilma@terra.com.br

${ }^{3}$ Mestre em Educação pela Universidade Federal de Uberlândia - UFU. Professora na Educação Infantil e Supervisora no Ensino Fundamental da Rede Pública Municipal de Ensino de Uberlândia. E-mail: andreaportoribeiro@gmail.com

${ }^{4}$ Mestrando pelo Instituto Federal de Educação, Ciência e Tecnologia do Triângulo Mineiro. Professor de Matemática da Rede Pública Municipal de Ensino de Uberlândia. E-mail: clebermat@ clebermat2.com
} 


\title{
RESEARCH ON BASIC EDUCATION PROFESSIONALS AND PUBLIC POLICIES FOR CONTINUING EDUCATION: RELEVANT DIALOGUES?
}

\begin{abstract}
This text addresses the adoption of qualitative research as public Policy Formation and structuring axis of action, presentation and analysis of results of research with professionals in the basic education, inspired by the action research (THIOLLENT, 2009), using the wheels of conversation (birth; SILVA, 2009) as production space and data analysis, dialogue and collective actions. The results showed the importance of research in the process of continuing education, on identification, clarification of issues, development of collective action and public policy. Demonstrated the need to ensure time and space for the conduct of research and the training of education professionals, by reducing the gap between traditional public educational policy makers and professionals.
\end{abstract}

Key words: Research; Continuing Education; Wheels of Conversation; Instrument of Public Policy Development.

\section{INVESTIGACIÓN CON PROFESIONALES DE EDUCACIÓN BÁSICA Y POLÍTICAS PÚBLICAS DE FORMACIÓN CONTINUADA: DIÁLOGOS PERTINENTES?}

\begin{abstract}
Resumen
El presente trabajo adopta el método de investigación cualitativa para analizar la política pública de formación continuada y el eje estructural de las acciones presentadas en el análisis de resultados de investigación con profesionales de la educación básica, según la investigación - acción (THIOLLENT, 2009), evaluando las ruedas de diálogos (NASCIMENTO; SILVA, 2009) como un espacio de producción y análisis de datos, conversaciones y elaboración de acciones colectivas. Los resultados comprueban la
\end{abstract}


importancia de la investigación en el proceso de formación continuada, su tipificación, aclaración de los conflictos, ejecución de las acciones colectivas y definición de las políticas públicas educacionales. En efecto, urge la necesidad de garantizar tiempo y espacio para la elaboración de una investigación con el eje en la formación continuada de los profesionales en la educación, disminuyendo la distancia entre los conservadores responsables en las políticas públicas y los profesionales señalados.

Palabras clave: Investigación; Formación continuada; Ruedas de diálogos.

\section{CONSIDERAÇÕES PRELIMINARES}

O diálogo é o encontro amoroso dos homens que, mediatizados pelo mundo, o pronunciam, isto é, o transformam, e, transformando-o, o humanizam para a humanização de todos [...] O diálogo problematizador não depende do conteúdo que vai ser problematizado. Tudo pode ser problematizado. (FREIRE, 1977, p. 43, 53).

A reflexão apresentada neste artigo acerca dos significados da pesquisa na/para a elaboração e desenvolvimento de políticas públicas ${ }^{5}$ de formação continuada com os/as profissionais da educação básica analisa as questões decorrentes do compromisso de elaborar e materializar Política Pública de Formação Continuada, vinculada às demandas e aos interesses formativos dos/as alunos/as e dos/as profissionais da rede pública de ensino. Essa formação deve se ocupar das situações que impactam a construção da qualidade social da educação a partir da realidade, comprometendo-se com a transformação das situações que provocam exclusão social e escolar.

A Política Pública de Formação não pode ficar alheia às críticas sobre os processos formativos e ao distanciamento da formação continuada das demandas e necessidades dos/as profissionais, dos/as alunos/as e das dinâmicas escolares. É preciso, portanto, optar por metodologias que favoreçam a indissociabilidade entre ensino, pesquisa e formação continuada transformando-a em momentos de produção e comunicação de conhecimentos acerca de diferentes dimensões da qualidade social da educação. Conforme ponderam Nunes e Novais (2017, p. 302),

\footnotetext{
${ }^{5}$ Adotamos uma concepção de política pública expressa na afirmativa "o que o governo escolhe fazer ou não fazer" (DYE, 1984).
} 
A concepção de qualidade da educação é aqui entendida de modo plural, com ênfase na relação do ensino e da aprendizagem. Portanto, destaca-se também os processos e as condições que os determinam como, por exemplo, o acesso, a permanência e a conclusão qualificada socialmente. Mas, lembrando que tudo isso não pode localizar-se somente no campo da medição, como pressupõe a maioria dos órgãos internacionais, incluindo o Banco Mundial, a Organização das Nações Unidas para a Educação, Ciência e Cultura - UNESCO, a Comissão Econômica para a América Latina e o Caribe - CEPAL, o Fundo das Nações Unidas para a Infância - UNICEF, o Ministério da Educação - MEC, o Instituto Ayrton Senna, a União Nacional de Dirigentes Municipais de Educação - UNDIME, dentre outros órgãos.

São necessários enfrentamentos teóricos e metodológicos para elaborar, coletivamente, política pública compromissada com a construção da escola pública, democrática, popular ${ }^{6} \mathrm{e}$ de qualidade social. A formação continuada (FREIRE, 1977, 1980; NÓVOA, 2001, 2009) deve considerar os sujeitos participantes dos processos de ensino e aprendizagem e seus grupos de convivência. A materialização dessa política requer ações ancoradas no reconhecimento do/a outro/a como sujeito produtor e comunicador de conhecimentos, na vivência do diálogo, na unicidade entre teoria e prática. Nesse processo, não há lugar para educação bancária (FREIRE, 1987). Por conseguinte, questionamos: a pesquisa deveria ser eixo estruturante do processo de elaboração, implementação e avaliação da política pública?

Assim, cabe rememorarmos questões presentes nas reflexões sobre política pública educacional desenvolvida na Secretaria Municipal de Educação - SME do município de Uberlândia, no período de 2013 a 2016, durante Encontros Regionais de Educação, Cursos, Congresso Municipal de Educação, Rodas de Conversa, Mostras Pedagógicas, dentre outros espaços formativos, e suas implicações no âmbito da escolha de conceitos e de metodologias favoráveis à compreensão e intervenção na realidade educacional, sobretudo quanto à formação continuada, visando garantir direitos educacionais.

Para ilustrar, citamos indagações recorrentes e evidenciadas durante o processo formativo: a política pública de formação continuada favorece a quem? O que o governo fez e ou deixou de fazer? Quem participa da elaboração, implementação e avaliação dessa política? Quais princípios e diretrizes ancoram a Política Pública de Educação? A política de formação continuada vincula-se a qual Projeto Político Pedagógico?

\footnotetext{
6 "A Educação Popular anuncia que entre as situações-limite, geradoras de violência, e os inéditos viáveis, expressão de Paulo Freire, que significa as possibilidades de superação das situações-limite, encontra-se a educação como ação reflexiva e como prática cultural comprometida com a luta em direção ao 'ser mais', dimensão ontológica do ser humano" (Marco de Referência da Educação Popular, 2014, p. 29).
} 
As críticas à formação continuada mostram a pertinência da adoção da pesquisa como seu eixo estruturante, mas outras questões surgem: o engajamento da formação continuada em um projeto educacional vinculado à construção da escola pública, popular, democrática e de qualidade social, enquanto ação coletiva, implica a escolha de epistemologia marcada por um modo de conceber a produção de conhecimento sem filiação às ciências positivas? Como manter as especificidades das unidades escolares e possíveis interpretações no processo de esclarecimento sobre problemas educacionais e de elaboração de ações visando à superação dos mesmos? Que tipo de pesquisa se mostraria adequada no/para o processo de produção coletiva de conhecimentos e intervenções pedagógicas no âmbito da unidade escolar?

Em vista disso, resgatamos e analisamos a experiência de elaboração e implementação de política pública educacional desenvolvida no município de Uberlândia, no período de 2013 a 2016, utilizando-se da pesquisa com os/as profissionais da educação para identificar, esclarecer problemas, produzir conhecimentos e intervir, coletivamente, na realidade educacional vinculada à qualidade social da educação. E, ainda, fortalecer as comunidades escolares como sujeitos produtores de conhecimentos e de estratégias transformadoras da realidade escolar.

$\mathrm{Na}$ primeira seção deste texto expomos sobre o contexto de produção da Política Pública de Educação desenvolvida no município de Uberlândia, no período citado, mostrando elementos da experiência que subsidiaram os contornos dessa política a partir dos resultados de uma primeira aproximação da realidade educacional do município e, posteriormente, a introdução da pesquisa com os/as profissionais da Rede Pública de Ensino tendo as Rodas de Conversa como espaço de diálogo e de escuta interessada para identificação, esclarecimento e elaboração de ações coletivas visando transformar a realidade educacional do município.

$\mathrm{Na}$ segunda, tratamos da pesquisa como eixo estruturante da política pública e descrevemos esse processo. Na terceira seção, apresentamos e analisamos os resultados e significados na/para a formação continuada com os/as profissionais da rede pública de ensino, articulada ao projeto de escola pública, popular, democrática e de qualidade social.

Finalmente, destacamos o potencial da pesquisa com os/as profissionais da educação como elemento fundamental para/na elaboração de Políticas Públicas Educacionais favoráveis à produção de conhecimentos acerca da realidade educacional e de ações coletivas, visando superar dificuldades identificadas nos processos de ensino e de aprendizagem e que fomentam 
desconhecimentos, exclusão ou participação excludente ${ }^{7}$ (NOVAIS, 2005) nas unidades escolares e em outros espaços sociais.

\section{O CONTEXTO DE PRODUÇÃO DA POLÍTICA PÚBLICA DE EDUCAÇÃO: 2013-2016}

A Rede Pública Municipal de Ensino de Uberlândia-MG possui 118 unidades escolares, sendo: 65 de educação infantil e 53 de ensino fundamental. 40 escolas de ensino fundamental são urbanas, incluindo o Campus de Atendimento à Pessoa com Deficiência e 13 rurais. Há, também, o Centro Municipal de Estudos e Projetos Educacionais Julieta Diniz - CEMEPE para formação dos/as profissionais da educação e, aproximadamente, 57.000 alunos/as ${ }^{8}$.

No primeiro semestre de 2013 investigou-se sobre a realidade educacional ${ }^{9}$ referente à Rede Municipal de Ensino orientada pela questão: qual a realidade educacional do município de Uberlândia, tendo em vista a qualidade social da educação? Essa questão se desdobrava em outras, contemplando as dimensões da qualidade da educação, a saber: demanda e oferta de vagas nas unidades de educação infantil, ensino fundamental e educação de jovens e adultos - EJA; infraestrutura; resultados educacionais; projetos desenvolvidos nas escolas; plano de cargos, carreira e salário dos/as profissionais da educação; formação inicial e contínua; violência escolar; gestão da educação; e, recursos previstos para a educação. Apresentamos, sucintamente, os resultados da investigação ${ }^{10}$ :

a) 10.200 crianças esperando por vagas nas unidades de educação infantil;

b) Demanda reprimida por educação de jovens e adultos - EJA em duas empresas: uma do ramo atacadista e outra da construção civil, em bairros periféricos da cidade; em Distrito; e em Assentamento;

\footnotetext{
${ }^{7}$ Segundo Novais (2005, p. 57), “[...] refere-se a um tipo de participação de determinados grupos de alunos /as na escola, uma vez que o modo de inserção no contexto escolar oferecido a esses grupos favorecia a construção de processos graduais de exclusão escolar. Processos estes, ancorados em mecanismos de desigualdades de oportunidades de permanência e terminalidade dos estudos".

${ }^{8}$ Dados relativos ao ano escolar de 2013 na Rede Municipal de Ensino da Secretaria Municipal de Educação de Uberlândia/MG.

${ }^{9}$ Fontes de dados: Relatórios da inspeção escolar da Rede Municipal de Ensino; observações realizadas nas unidades escolares por assessores/as e secretária; registros PDDE; Plano de Ações Articuladas - PAR; arquivo de Ordem de Serviço - O.S. sobre infraestrutura; Portal do SIMEC; fotografias e registro de diálogos com a população sobre demanda por vagas; relatórios de avaliações sistêmicas (PROEB, PROALFA E IDEB). Pesquisa realizada por um grupo de assessores/as e professores/as da equipe do CEMEPE sob a coordenação do Comitê Gestor.

10 Fonte: Relatório de Gestão (2013/2016), disponível no arquivo da Secretária Municipal de Educação de Uberlândia.
} 
c) Aproximadamente 400 alunos/as de ensino fundamental esperando por vagas;

d) Em torno de $90 \%$ das escolas necessitando de reformas e manutenções: instalações elétricas, provocando riscos de acidentes e impossibilitando manter ligados equipamentos de laboratórios e outros necessários ao funcionamento das unidades escolares; telhados com defeitos; banheiros estragados; extintores vencidos; anexos de escolas de Educação Infantil sem infraestrutura adequada; solicitações de serviço de manutenção feitas há mais de cinco anos e não atendidas;

e) Espaço físico insuficiente em unidades escolares (quantidade insuficiente de salas para ministrar aulas de artes, salas de professores/as, de multiuso, secretarias e para realização de atividades e projetos interdisciplinares);

f) Parcela de mobiliário estragada ou em quantidade deficitária (mesas, carteiras, armários);

g) Parcela significativa de alunos/as matriculada com resultados insatisfatórios na construção de conhecimentos nas áreas das linguagens, das ciências, das artes e da convivência humana;

h) Projetos desenvolvidos sobre leitura e escrita, relações de gênero, raça/etnia, educação ambiental, relação família/escola, festas tradicionais, hortas nas escolas, recuperação, dentre outros temas. Porém, a maioria sem envolvimento de todos os membros da equipe da unidade escolar, acarretando sobrecarga para parcela dos/as profissionais da educação comprometida com a elaboração e desenvolvimento dos projetos. O trabalho coletivo e a adoção da perspectiva interdisciplinar não estavam presentes em parcela significativa das escolas;

i) Plano de Cargos e Carreira - PCC - dos/as profissionais da educação sem revisão há mais de 10 anos;

j) Gestão educacional piramidal e sem mecanismos de democratização;

k) Ausência de gestão interinstitucional e interárea e sem interlocução entre as secretarias e outros órgãos da Prefeitura;

1) Dotações orçamentárias e financeiras insuficientes para atender demanda reprimida por vagas e melhoria da infraestrutura das unidades escolares;

m) A maioria dos/as docentes com formação inicial adequada: graduação e pós-graduação lato sensu, conforme mostra o quadro 1 ; 


\begin{tabular}{|c|c|c|c|c|c|c|c|c|}
\hline Cargo & $\begin{array}{l}\text { Ensino } \\
\text { Fundamental }\end{array}$ & $\begin{array}{l}\text { Ensino } \\
\text { Médio }\end{array}$ & $\begin{array}{l}\text { Ensino } \\
\text { Superior }\end{array}$ & $\begin{array}{l}\text { Especializa } \\
\text { ção }\end{array}$ & Mestrado & Doutorado & $\begin{array}{c}\text { Pós- } \\
\text { doutorado }\end{array}$ & Total \\
\hline $\begin{array}{c}\text { Operacion } \\
\text { al }\end{array}$ & 525 & 897 & 49 & 7 & 0 & 0 & 0 & 1478 \\
\hline $\begin{array}{l}\text { Administr } \\
\text { ativo }\end{array}$ & 8 & 197 & 104 & 93 & 7 & 2 & 0 & 411 \\
\hline $\begin{array}{c}\text { Educador/ } \\
\text { a infantil }\end{array}$ & 11 & 796 & 319 & 197 & 7 & 0 & 0 & 1330 \\
\hline $\begin{array}{c}\text { Professor/ } \\
\text { a }\end{array}$ & 0 & 76 & 1314 & 2441 & 132 & 2 & 1 & 3966 \\
\hline $\begin{array}{c}\text { Diretor/a e } \\
\text { vice- } \\
\text { diretor/a } \\
\text { de escola }\end{array}$ & 0 & 5 & 44 & 165 & 7 & 0 & 0 & 221 \\
\hline $\begin{array}{c}\text { Instrutor/a } \\
\mathrm{e} \\
\text { interprete } \\
\text { de } \\
\text { Libras }\end{array}$ & 0 & 4 & 6 & 7 & 0 & 0 & 0 & 17 \\
\hline $\begin{array}{l}\text { Especialist } \\
\text { a ou } \\
\text { Pedagogo/ } \\
\text { a } \\
\end{array}$ & 0 & 0 & 43 & 248 & 31 & 1 & 0 & 323 \\
\hline Total & 544 & 1975 & 1879 & 3158 & 184 & 5 & 1 & 7746 \\
\hline
\end{tabular}

Fonte: Quadro organizado pela Assessoria de Desenvolvimento Humano, com base nos dados contidos nos documentos oficiais da Secretaria Municipal de Educação - SME, em 23/09/2013.

n) Em torno de $20 \%$ dos/as docentes e especialistas ou pedagogos/as participando de formação continuada.

Outro resultado da investigação foi a queixa recorrente apresentada por parcela significativa dos/as profissionais da educação sobre a formação continuada e a ausência de vínculo da formação com a realidade da escola.

Diante dos resultados e da necessidade de aprofundar a análise coletiva dos problemas, buscar percepções sobre a realidade em cada unidade escolar e de elaborar, desenvolver e avaliar, coletivamente, ações pedagógicas, a proposição da equipe gestora da Secretaria Municipal de Educação - SME foi a de optar pela pesquisa qualitativa com os/as profissionais da educação como estratégia de elaboração da política pública de educação e eixo estruturante dessa política e das ações dela decorrentes, buscando inspiração na pesquisa-ação. Como escreve Barbie (2002, p. 54):

A pesquisa-ação reconhece que o problema nasce, num contexto preciso, de um grupo em crise. O pesquisador não o provoca, mas constata-o, e seu papel consiste em ajudar a coletividade a determinar todos os detalhes mais cruciais ligados ao 
problema, por uma tomada de consciência dos atores do problema numa ação coletiva.

Ao desenvolver a pesquisa com os/as profissionais da educação discutiu-se, na Comissão de Elaboração de Proposta do Calendário Escolar, para o ano letivo de 2015, composta por representantes dos/as diversos profissionais que atuam na escola e outros membros da equipe da SME lotados na administração, os seguintes temas: 1. O caráter pedagógico do Calendário Escolar e seus vínculos com os Projetos Políticos Pedagógicos; 2. A necessidade de incluir, no Calendário Escolar, discussões coletivas sobre diferentes a realidade educacional; 3. A inclusão das Rodas de Conversa no Calendário.

Outra ação foi a criação de espaços de formação com os/as diretores/as das escolas, inspetores/as, professores/as, orientadores/as, supervisores/as escolares acerca das Rodas de Conversa e resultados educacionais compartilhando base teórica e metodológica e significados das Rodas como espaço de produção e análise dos dados sobre diferentes aspectos da realidade escolar e de elaboração coletiva de propostas. Esse processo visava sensibilizar profissionais da educação para a participação na pesquisa, com as Rodas de Conversa, destacando a importância de todos/as participarem e de articular a formação continuada com resultados da investigação sobre demandas formativas. Visava estabelecer registros escritos e fotográficos das Rodas e o uso dos conteúdos dos registros para subsidiar a Política Pública de Educação da Rede Municipal de Ensino de Uberlândia e suas ações.

\section{NARRATIVAS SOBRE A EXPERIÊNCIA DE PESQUISA COM OS PROFISSIONAIS DA EDUCAÇÃO: A FORMAÇÃO EM MOVIMENTO}

Ninguém luta contra as forças que não compreende, cuja importância não mede, cujas formas e contornos não discerne. (FREIRE, 1980, p. 40.)

A investigação inicial, no ano de 2013, colocou à disposição do/a gestor/a público/a dados sobre a realidade educacional. Mas, era preciso desencadear processo que trouxesse à tona detalhamento e percepções dos problemas identificados, definições sobre o que os grupos das escolas consideravam como problema que impactava o cumprimento de objetivos educacionais ou que não constava nos resultados da primeira investigação. Além disso, fomentasse a tomada de consciência dos/as profissionais que atuam no cotidiano das unidades escolares do município e a produção de conhecimentos coletivos sobre os problemas e possíveis ações vinculadas à transformação da realidade educacional. 
A decisão foi desenvolver pesquisa de natureza qualitativa, inspirada na pesquisa-ação, especialmente a discussão sobre a função política dessa pesquisa e seus objetivos. Como argumenta Thiollent (2009, p. 47), “a função política da pesquisa-ação é intimamente relacionada com o tipo de ação proposta e os atores considerados. A investigação está valorativamente inserida numa política de transformação".

A decisão de envolver as unidades escolares dos cinco polos ${ }^{11}$ em processos investigativos evidenciou desafios vinculados ao reconhecimento de que cada unidade escolar era espaço específico de pesquisa. O espaço criado para realizar essas ações foi o da Roda de Conversa fundada no princípio de que, a Roda:

[...] não tem dono(a). Todos (as) podem participar. Todos (as) podem chamar para iniciar a roda. O ritmo da roda é ditado por quem dela participa. Para fazer girar a roda precisa de elos entre os (as) participantes, por isso é necessário à constituição de disposição para aceitar regras de convivência e a participação democrática e cidadã de todos (as). A roda é alimentada pelo prazer de estar juntos (as) [...] Se alguém entra para a roda passa a ocupar todos os lugares, na medida em que a roda gira. Os(as) participantes vão eleger quais cantigas (temas, as questões sobre esses temas, a metodologia, os materiais de apoio etc.), dia, horário e tempo de duração da roda. A roda deve ter formas de registro resguardando a memória da roda. (NOVAIS; NOVAIS, 2009, p. 2).

Martins (2004, p. 292) reconhece que, "Se há uma característica que constitui a marca dos métodos qualitativos ela é a flexibilidade, principalmente quanto às técnicas de coleta de dados, incorporando aquelas mais adequadas à observação que está sendo feita.”

A Roda de Conversa foi utilizada como instrumento de produção e análise de dados, de elaboração e avaliação de ações coletivas frente aos problemas identificados. Cada Roda era única, com as marcas dos/as participantes e do contexto escolar, mas havia a sugestão de estrutura comum. O tempo era dividido em três momentos: 1) Aquecimento; 2) Desenvolvimento; 3) Encerramento e Avaliação.

\footnotetext{
${ }^{11}$ A Lei 11.444/2013, promulgada no município de Uberlândia criou a Rede Pública Municipal pelo Direito de Ensinar e de Aprender composta por representantes do Poder Executivo Municipal, sociedade civil, entidades e organizações sociais e pelos cinco Polos correspondentes aos setores territoriais: Norte, Sul, Leste, Oeste e Centro. Dentre os objetivos desta Lei, publicada no Diário Oficial do Município - DOM, de 26 de julho de 2013, citamos: "[...] V - favorecer a construção da cultura de cooperação, acompanhamento, avaliação das ações relativas ao enfrentamento das múltiplas causas do baixo rendimento e da evasão escolar; VI - ampliar possibilidades de construção coletiva de programas e serviços que atuem no enfrentamento das dificuldades de escolarização e na melhoria do desenvolvimento educacional; (...); XII - fomentar a atuação conjunta para resolver problemas educacionais de atuação das instituições (...); XIII - garantir um ambiente propício ao direito de ensinar e aprender [...]”. (Prefeitura Municipal de Uberlândia, 2013).
} 
1. AQUECIMENTO: Para sensibilização do grupo será desenvolvida uma dinâmica com a finalidade de integrar e sensibilizar os participantes da Roda de Conversa Temática para participarem da conversa sobre o tema, elaborarem e avaliarem intervenções com vistas à superação dos problemas identificados.

2. DESENVOLVIMENTO: Discussão provocada por indagações e apresentação de dados construídos durante a análise de documentos.

3. ENCERRAMENTO E AVALIAÇÃO nesse momento serão realizadas avaliações da Roda, estabelecidos encaminhamentos e indicação do novo tema da próxima Roda. Durante as Rodas, serão produzidos registros escritos que serão lidos e aprovados na próxima Roda. (SECRETARIA MUNICIPAL DE EDUCAÇÃO DE UBERLÂNDIA, 2014, p. 8).

Os registros das Rodas, escritos e fotográficos, foram encaminhados à SME para leitura e deliberações relativas ao material de apoio e estrutura física das escolas. As propostas relativas à formação continuada foram incluídas no Plano de Formação da Escola ou no Plano de Formação do CEMEPE. Nascimento e Silva (2009) afirmam que:

\begin{abstract}
As rodas de conversa, metodologia bastante utilizada nos processos de leitura e intervenção comunitária, consistem em um método de participação coletiva de debates acerca de uma temática, através da criação de espaços de diálogo, nos quais os sujeitos podem se expressar e, sobretudo, escutar os outros e a si mesmos. Tem como principal objetivo motivar a construção da autonomia dos sujeitos por meio da problematização, da socialização de saberes e da reflexão voltada para a ação. Envolve, portanto, um conjunto de trocas de experiências, conversas, discussão e divulgação de conhecimentos entre os envolvidos nesta metodologia. (NASCIMENTO; SILVA, 2009, p. 1).
\end{abstract}

As dificuldades no processo de implementação da Pesquisa foram decorrentes das necessidades e condições de investigação: a) nenhuma experiência coletiva de pesquisa com a Rede. b) Tempo escasso para discussão coletiva. c) Resquícios da adesão à uma Cultura de elaboração de Políticas Públicas sem a participação ativa das comunidades escolares. d) A necessidade de abdicar-se da ideia de que o grupo de pesquisador/a seria o da assessoria da SME e constituir os grupos com a participação dos/as profissionais que atuavam na escola, no CEMEPE e na SME.

O processo da pesquisa iniciou-se no segundo semestre de 2014, crivado de incertezas e desafios colocando em movimento processos formativos. Assessorias da SME e equipes do CEMEPE convidaram para a reflexão coletiva os/as profissionais das escolas, no CEMEPE e no Centro Administrativo da Prefeitura. Nesses encontros, de dezembro de 2014 a junho de 2015, foram discutidos temas, como: leitura dos dados relativos à realidade escolar do município e seus significados na construção da qualidade social da educação; organização do tempo e espaço escolar para a realização das Rodas de Conversa e a organização dessas 
Rodas; análise dos registros das Rodas e propostas de ação. As equipes das escolas mediavam as Rodas com o apoio da equipe do CEMEPE e da SME que esclareciam sobre a metodologia e auxiliavam na sistematização dos dados coletados.

Os registros foram sistematizados por Polos e analisados a partir dos eixos temáticos, considerando: a) formação; b) apoio administrativo; c) marcenaria; d) desenvolvimento humano; e) transporte escolar; f) relação família-escola; g) indisciplina na escola; h) outras questões.

Os encaminhamentos relativos às Propostas Pedagógicas presentes nos registros das Rodas foram consolidados e expostos pelos/as diretores/as e vice-diretores/as das unidades escolares de cada Polo, em reuniões no CEMEPE. Após as apresentações, ocorreram discussões, sugestões e possibilidades de ações compartilhadas. Os registros foram encaminhados à SME e à cada assessoria para análise e desenvolvimento de ações visando materializar a Política Pública de Educação nas áreas de Apoio Administrativo (reforma e manutenção, material de apoio pedagógico); Marcenaria (mobiliário novo e reforma); Programa de Alimentação Escolar; Desenvolvimento Humano; Assessoria Pedagógica; Formação Continuada; e Transporte Escolar. As ações foram consolidadas em um documento intitulado "Devolutivas Sobre as Demandas das Rodas".

\section{RESULTADOS E SEUS SIGNIFICADOS NA/PARA A POLÍTICA DE FORMAÇÃO CONTINUADA COM OS/AS PROFISSIONAIS DA REDE PÚBLICA DE ENSINO}

Para examinarmos os significados da pesquisa para a elaboração e implementação da Política Pública de Educação é fundamental retomarmos as Rodas de Conversa, instrumento de produção de dados, diálogo e elaboração de propostas, rememorando a especificidade de cada Roda (dinâmica, tema, problematização, encaminhamentos, fundamentos teóricos das discussões, dentre outros aspectos).

Durante a primeira Roda de Conversa, na Escola do/a Aprendiz ${ }^{12}$, sobre avaliação, no momento de aquecimento foram retomados os objetivos da Roda: "fomentar diálogo na escola, ouvir as indagações e construir juntos projetos em busca de soluções para as dificuldades" (Registro da Roda de Conversa da Escola do/a Aprendiz, 2014) e, em seguida,

\footnotetext{
${ }^{12}$ Nome fictício, visando preservar compromisso de sigilo.
} 
os/as participantes assistiram e discutiram o conteúdo de um vídeo. Para melhor descrever a continuidade da Roda, vejamos trecho de um dos registros produzidos:

Vídeo: "A Morte do Cisne Branco" - John Lennon da Silva

Discussão:

Houve uma discussão sobre o filme, o "pré-conceito", a depreciação do candidato, o que chama a atenção é o meio como o dançarino é visto pelos avaliadores.

A avaliação foi colocada como a "arma do professor", para controle da disciplina.

O professor deve desmistificar essa visão e nas aulas devem trabalhar valores e estimular mudanças.

Comunidade envolvida com o tráfico, que dificulta o trabalho dos professores.

Destacou a questão de avaliar a partir das habilidades e que as avaliações externas propostas pelo governo distanciam da maneira da escola avaliar.

Discutiu-se que os alunos não sabem ler e escrever. O que fazer?

São situações que desestimulam o trabalho, questões políticas que influenciam e prejudicam o desempenho escolar.

Encaminhamentos: Escola:

1- Usar essa metodologia (Roda de Conversa) como rotina para diálogos sobre problemas e indagações vivenciadas na escola;

2- Temas para a próxima Roda: Manhã: Avaliação; Tarde: Avaliação e Noite: $O$ trabalho que a escola realiza com projetos;

3- Pensar algumas estratégias diferentes de avaliação que pudessem ser aplicadas/ministradas na escola; priorizar 0 processo;

4- $\quad$ "O que fazer com os alunos apáticos e desinteressados, mas que cedinho estão na porta da escola?"

5- Ministrar aulas em salas temáticas (salas laboratórios) que atendam as reais necessidades de aprendizagem e conhecimento discente.

Palavras finais:

"O que vocês acharam da roda?".

Clarearam algumas coisas; proveitoso, é bom ouvir os outros; troca de aprendizados; ver a experiência do colega; precisa acontecer com mais frequência para que nos conheçamos melhor e possamos nos ajudar; deve continuar; agregar conhecimento; esclarecimentos; esperança; precisa acontecer sempre; encontros 
são importantes até mesmo para o professor que está acomodado: momento para repensar a prática da avaliação; bom; novidade; ouvir o colega para a gente também mudar; socializar ideias $e$ experiências; sementes lançadas que serão frutificadas, adquirir raízes e crescer; importante para trocar experiências; incertezas; envolvimento com o aluno para que ele aprenda e não somente passe de ano; experiências.

Reflexão, entusiasmo; novidade; expectativa; e aí, o que fazer? disposição; questionamento; início; será uma luz?; pré-disposição para mudar; não haverá muitas mudanças, somente exposições de opiniões; outro tema: desinteresse do aluno; começo, ação.

As rodas foram finalizadas com palmas (Registro da Roda de Conversa da Escola do/a Aprendiz, 2014).

Analisando esse registro, denota-se que a Roda de Conversa se constituiu em espaço de formação dialogada que, problematizando as questões apresentadas pelos/as diferentes participantes, buscou consensos, ainda que provisórios, para implantar as ações no âmbito da escola. O diálogo evidenciou demandas formativas a serem incluídas no Plano de Formação da Escola ou do CEMEPE. A Roda permitiu estabelecer projetos para superar problemas do dia a dia da escola e que foram evidenciados no diálogo acerca da avaliação trazendo elementos do contexto do ensino e da aprendizagem. Em relação à formação, vejamos trecho do Plano de Formação na Escola do/a Aprendiz, elaborado com base nas reflexões oriundas da Roda, intitulado "Indisciplina e Planejamento Pedagógico - traçando novas estratégias".

Após a Roda de Conversa realizada na primeira semana letiva deste ano, a equipe de professores demonstrou preocupação com a questão da indisciplina dos alunos e a necessidade de traçar estratégias para otimizar o trabalho pedagógico, a conduta escolar e as relações entre alunos e professores em nossa escola. Partindo destas reflexões, foi definido o tema "Indisciplina $e$ Planejamento Pedagógico - traçando novas estratégias" para projeto de formação continuada in loco na Escola do Aprendiz no ano de 2016, atendendo a Lei Municipal 11.444/2013 Rede Pública Municipal pelo Direito de Ensinar e aprender. [...].

\section{Objetivo geral:}

Discutir, analisar, refletir sobre as causas da indisciplina no contexto escolar e como a gestão de sala de aula pode contribuir para diminuir os conflitos nas relações de convivência.

\section{Objetivos específicos:}


Módulo I - Refletindo sobre o tema "Indisciplina"

- Promover momentos de estudo em que os docentes possam refletir sobre sua própria postura pedagógica e como 0 planejamento prévio do trabalho pode auxiliar na diminuição da indisciplina.

Módulo II - Estudar para enriquecer a prática pedagógica - Propiciar a aplicação de novas estratégias em nossa escola;

- Estimular práticas pedagógicas e planejamentos direcionados ao combate à indisciplina.

- Estimular os alunos a mudar de postura no ambiente escolar.

Módulo III - Compartilhando resultados

- Compartilhar as experiências e resultados dos projetos desenvolvidos pelos professores ao longo do ano;

- Avaliar a formação continuada e seus resultados a curto e longo prazo no ambiente escolar.

- Refletir como os estudos desenvolvidos em nossa escola contribuíram para a formação profissional dos docentes [...]. (Plano de Formação - Escola do/a Aprendiz, 2016).

Em relação à metodologia adotada para a formação na escola, consta do registro da Roda de Conversa:

Os estudos serão conduzidos a partir da leitura e discussão de textos informativos, artigos acadêmicos e documentos institucionais que servirão de base para a elaboração de projetos coletivos de aplicação em nossa própria escola. Estão previstas palestras, rodas de conversa, estudos de caso, apresentação de slides e filmes que contribuam para o desenvolvimento das atividades ao longo do ano. Após a aplicação dos projetos, serão feitos encontros para trocas de experiência sobre as mudanças feitas na prática pedagógica, reflexões sobre os resultados apresentados e como a formação contribuiu para a mudança do quadro inicial de indisciplina apresentado no início de 2016 e anos anteriores (Registro da Roda de conversa da Escola do/a Aprendiz, 2016).

Os resultados das análises dos registros das Rodas de Conversas das outras unidades escolares também permitiram reconhecê-las como espaços formativos e de problematização da realidade escolar: os problemas, as práticas pedagógicas e seus fundamentos, as políticas públicas (o que o governo faz ou deixa de fazer ${ }^{13}$ ). Destacou-se que a formação foi ampliada

\footnotetext{
${ }^{13}$ Ver nota de rodapé 5.
} 
e, além dos conteúdos a serem ensinados, foram tratados aspectos da condição de ensinar e de aprender (espaço físico, transporte, alimentação escolar, material de apoio pedagógico, Regimento Escolar, Plano de Cargos e Salários, quantidade de alunos/as por turmas).

Outros resultados apresentados a partir da análise dos registros das Rodas foram os diferentes temas ali tratados e o questionamento sobre a possibilidade de transformar o/a professor/a em pesquisador/a, em contexto de ausência de tempo para estudos. O questionamento foi feito em uma Roda, mas tem relevância considerando a reflexão sobre a adoção da pesquisa como eixo estruturante da Política Pública para as unidades de ensino.

Os assuntos refletidos nas Rodas de Conversa indicaram que as temáticas recorrentes e problematizadas se relacionavam com a área de desenvolvimento humano, especificamente relações interpessoais; da formação, principalmente sobre educação especial, sexualidade, relação família/escola e indisciplina. O tema de cada Roda foi proposto pela própria unidade escolar. Entretanto, em função da dinâmica oriunda das interações sociais subjetivas e objetivas, o tema objeto de reflexão se manteve ou foi alterado em função da necessidade de cada grupo.

Consciente das temáticas de problematização, a unidade escolar elaborou planos de ações para intervenção na realidade a ser transformada, consolidando a parceria com a Universidade Federal de Uberlândia e o CEMEPE, no tratamento de assuntos relativos à sexualidade com os/as docentes e discentes, proporcionando a formações in loco a fim de superar as dificuldades enfrentadas pelos/as profissionais da educação.

Os resultados da análise dos registros permitiram elaborar o Quadro 2, sobre a formação e a prática pedagógica e os compromissos assumidos pelas escolas componentes dos Polos: Centro, Norte, Sul, Leste, Oeste. A leitura do quadro 2 permite afirmar que as reflexões sobre problemas provocaram demandas formativas e evidenciaram a necessidade de reelaboração do Projeto Político Pedagógico e do Regimento escolar.

QUADRO 2 - FORMAÇÃO / PRÁTICAS PEDAGÓGICAS E COMPROMISSOS PARA 2015

\begin{tabular}{|l|l|l|l|}
\hline \multicolumn{2}{|c|}{ Escolas - Polos } & \multicolumn{1}{|c|}{ Formação e prática pedagógica } & \multicolumn{1}{c|}{ Compromissos para 2015 } \\
\hline $\begin{array}{l}\text { Escolas Municipais do } \\
\text { Polo Centro }\end{array}$ & $\begin{array}{l}\text { Atendimento Educacional Especializado: } \\
\text { qualificar o/a profissional regente de sala - } \\
\text { oferecer formação contínua; }\end{array}$ & $\begin{array}{l}\text { Formação permanente } \\
\text { profissionais da educação }\end{array}$ \\
\hline $\begin{array}{l}\text { Escolas Municipais do } \\
\text { Polo Leste }\end{array}$ & $\begin{array}{l}\text { Indisciplina: materializar o Projeto Político } \\
\text { Pedagógico -PPP; realizar Rodas de } \\
\text { Conversa com alunos/as; criar momentos } \\
\text { para trocas de experiências no interior da }\end{array}$ & Reelaboração do PPP \\
\hline
\end{tabular}




\begin{tabular}{|c|c|c|}
\hline & escola. & \\
\hline $\begin{array}{l}\text { Escolas Municipais do } \\
\text { Polo Norte }\end{array}$ & $\begin{array}{l}\text { Formação continuada que atenda às } \\
\text { necessidades dos/as professores/as para } \\
\text { promover encontros de formação em que se } \\
\text { sinta partícipes do processo, e não } \\
\text { receptáculos de informações. Proporcionar } \\
\text { espaços/encontros/visitas in loco para troca } \\
\text { de experiências. }\end{array}$ & $\begin{array}{l}\text { Formação permanente com os/as } \\
\text { profissionais da educação, tomando } \\
\text { como foco da formação a } \\
\text { problematização das práticas } \\
\text { pedagógicas. }\end{array}$ \\
\hline $\begin{array}{l}\text { Escolas Municipais do } \\
\text { Polo Oeste }\end{array}$ & $\begin{array}{l}\text { Realizar formação "in loco" a fim de } \\
\text { melhorar a compreensão e socialização dos } \\
\text { dados do Índice de Desenvolvimento da } \\
\text { Educação Básica - IDEB. }\end{array}$ & $\begin{array}{l}\text { Formação permanente } \\
\begin{array}{l}\text { profissionais da os } \\
\text { problematizando } \\
\text { pedacação, } \\
\text { pedagógicas. }\end{array}\end{array}$ \\
\hline $\begin{array}{l}\text { Escolas Municipais do } \\
\text { Polo Sul }\end{array}$ & $\begin{array}{l}\text { Relativo à indisciplina: criar e padronizar } \\
\text { regras de convivência para o ambiente } \\
\text { escolar e inseri-las no PPP; estudar PPP e } \\
\text { Regimento Escolar. }\end{array}$ & $\begin{array}{l}\text { Reelaboração do PPP e do } \\
\text { Regimento Escolar }\end{array}$ \\
\hline
\end{tabular}

Fonte: Dados organizados pelos/as autores/as, com base nos registros das Rodas de Conversa nas unidades escolares, 2015.

Assim, os registros das Rodas fundamentaram a elaboração e articulação dos planos formativos do CEMEPE e das unidades escolares construindo, coletivamente, a formação in loco - nas escolas e outros espaços da cidade alcançando os objetivos coletivos pactuados pela Rede Pública Municipal de Ensino de Uberlândia. Os registros das Rodas eram encaminhados para a SME visando tomadas de providências. Vejamos o quadro 3:

QUADRO 3- DEVOLUTIVAS RELATIVAS ÀS RODAS DE CONVERSA POR SETORES DA SME

\begin{tabular}{|c|c|c|}
\hline Setor & Tipos de demandas & $\begin{array}{c}\text { Quantidade de } \\
\text { devolutivas }\end{array}$ \\
\hline $\begin{array}{l}\text { Assessoria Pedagógica da Educação } \\
\text { Infantil }\end{array}$ & Políticas Públicas, Orientações Pedagógicas. & 15 \\
\hline $\begin{array}{l}\text { Assessoria Pedagógica do Ensino } \\
\text { Fundamental }\end{array}$ & Políticas Públicas, Orientações Pedagógicas. & 42 \\
\hline $\begin{array}{l}\text { Centro Municipal de Estudos e } \\
\text { Projetos Educacionais Julieta Diniz } \\
\text { - CEMEPE }\end{array}$ & Formação Continuada. & 46 \\
\hline Desenvolvimento Humano & $\begin{array}{l}\text { Diminuir a rotatividade e aumentar a } \\
\text { quantidade de profissionais, melhorar } \\
\text { relações interpessoais nas escolas, aumentar } \\
\text { o salário e divulgar os projetos sobre saúde } \\
\text { do/a servidor/a. }\end{array}$ & 34 \\
\hline Apoio Administrativo & $\begin{array}{l}\text { Infraestrutura, manutenção } \begin{array}{r}\text { escolar, } \\
\text { equipamentos, } \\
\text { administrativos. }\end{array} \\
\text { materiais }\end{array}$ & 62 \\
\hline Centro de Recursos Tecnológicos & Suporte tecnológico. & 05 \\
\hline Marcenaria & Produção e reforma de mobiliário. & 09 \\
\hline $\begin{array}{l}\text { Programa Municipal de } \\
\text { Alimentação Escolar - PMAE }\end{array}$ & $\begin{array}{l}\text { Alimentação (Revisar per capita } \\
\text { determinadas escolas). }\end{array}$ & 11 \\
\hline TOTAL & & 224 \\
\hline
\end{tabular}


Fonte: Dados organizados pelos/as autores/as, com base nos documentos oficiais da SME de Uberlândia, 2015.

Foram 224 solicitações envolvendo dimensões educacionais, desde a infraestrutura até a formação, conforme evidenciado no Quadro 3 e que possibilitaram estruturar as políticas da SME e pactuar acordos coletivos para o ano letivo/escolar de 2015, com a finalidade de alcançar processos educativos com qualidade socialmente referenciada.

\section{CONSIDERAÇÕES PERTINENTES}

Os resultados da pesquisa com os/as profissionais da educação do município de Uberlândia permitem destacar considerações acerca da pertinência da pesquisa como política pública e estratégia de elaboração dessa política. E, nesse processo investigativo, a tentativa de transformar as comunidades escolares em comunidades de investigação e elaboração de ações coletivas. No decorrer do texto expusemos dados e reflexões e optamos por realçar três considerações.

A primeira refere-se ao fato de que a pesquisa com os/as profissionais da educação destaca-se como alicerce fundamental para o desenvolvimento de Políticas Públicas Educacionais favoráveis à elaboração de conhecimentos sobre a realidade educacional e de ações coletivas para superar o senso comum, que expressa a ideologia direcionada ao interesse hegemônico e conservador e que não dialoga, de modo horizontal, com as comunidades das escolas públicas (PATTO, 1993). Nesse processo, a investigação realizada com foco na identificação, detalhamento e percepções dos problemas, bem como na produção coletiva de conhecimentos e possíveis ações vinculadas à transformação da realidade educacional criou espaço de formação continuada e de formulação de demandas para gestor/a público/a, revelando conteúdos e sentidos para as políticas públicas de educação.

A segunda consideração vincula-se ao potencial das Rodas de Conversa, espaço de problematização, diálogo e produção coletiva de conhecimentos fundamental, para elaboração das políticas públicas educacionais e das ações que as materializam e fortalecem a autonomia dos sujeitos. A Roda é espaço de formação para resolução de problemas coletivos, construção de ações educacionais com fundamentos teórico-científicos. Possibilita desenvolver, coletivamente, ações com sentidos e significados relativos à vida dos sujeitos escolares melhorando a qualidade social da educação. 
A terceira refere-se à necessidade de garantir tempo e espaços escolares favoráveis à adoção da pesquisa como eixo da formação de profissionais da educação e de alunos/as da rede pública de ensino básico.

Por fim, com base nos dados e reflexões apresentados, reafirma-se a pertinência do diálogo entre pesquisa, formulação e desenvolvimento de políticas públicas de educação. Reafirma-se, ainda, a necessidade de continuar o investimento na escola como espaço de produção de conhecimentos sobre a realidade escolar e o fim do distanciamento entre os/as tradicionais formuladores/as de políticas públicas educacionais e os/as profissionais que atuam no cotidiano das escolas públicas. 


\section{REFERÊNCIAS}

BARBIER, René. A pesquisa-ação. Brasília: Liber Livro, 2002.

BRASIL. Marco de Referência da Educação Popular para as Políticas Públicas. Brasília: Secretaria Geral da Presidência da República, 2014. Disponível em: <http://conae2014.mec.gov.br/images/pdf/MarcodeReferencia.pdf〉. Acesso em: 27 jan. 2015 .

DYE, Thomas D. Understanding Public Policy, Englewood Cliffs. N.J.: Prentice- Hall, 1984.

FREIRE, Paulo. Extensão ou comunicação? Rio de Janeiro: paz e Terra, 1977.

- Conscientização: teoria e prática da libertação - uma introdução ao pensamento de Paulo Freire. 3. ed. São Paulo: Moraes, 1980.

Pedagogia do oprimido. 17. ed. Rio de Janeiro: Paz e Terra, 1987.

MARTINS, Heloisa Helena Teixeira de Souza. Metodologia Qualitativa de Pesquisa. Educação e Pesquisa, v.30, n.2, p. 289-300, maio/ago. 2004.

NASCIMENTO, Maria Anezilany Gomes; SILVA, Cícero Nilton Moreira. Rodas de Conversa e Oficinas Temáticas: experiências metodológicas de ensino-aprendizagem em geografia. Disponível em: <http://www.agb.org.br/XENPEG/artigos/Poster/P\%20(36).pdf>. Acesso em: 16 fev.2016.

NOVAIS, Gercina Santana. A participação excludente na escola pública: um estudo sobre as representações de aluno, escola e prática pedagógica. 2005. 239 f. Tese (Doutorado em Educação). Faculdade de Educação/USP, São Paulo.

NOVAIS, Gercina Santana; NOVAIS, Eliane Santana. As Rodas de Conversa. Uberlândia, 2009. 6 f. Não publicado.

NÓVOA, António. Professor se forma na escola. Revista Nova Escola. São Paulo: Associação Nova Escola, Edição 142, maio. 2001.

Professores: imagens do futuro presente. Lisboa: Educa, 2009.

NUNES, Silma do Carmo; NOVAIS, Gercina Santana. A qualidade da educação na rede pública municipal de educação de Uberlândia/MG: análise das concepções, atitudes e ações dos/as gestores/as das unidades escolares. Ensino Em Re-Vista, Uberlândia/MG: v.24, n.02, p.295-316, jul./dez. 2017. 
PATTO, Maria Helena de Souza. A produção do fracasso escolar: histórias de submissão e rebeldia. São Paulo: T. A Queiroz, 1993.

THIOLLENT, Michel. Metodologia da pesquisa-ação. São Paulo: Cortez, 2009.

UBERLÂNDIA. Lei 11.444, de 24 de julho de 2013. Institui a Rede Pública Municipal pelo direito de ensinar e de aprender no município de Uberlândia e dá outras providências. Diário Oficial do Município, 26 de jul. 2013. Disponível em: <http://www.uberlandia.mg.gov.br/uploads/cms_b_arquivos/9242.pdf>. Acesso em: 24 jun. 2016.

SECRETARIA MUNICIPAL DE EDUCAÇÃO DE UBERLÂNDIA. Orientações teóricas/práticas elaboradas com gestores/as um convite a todos/as os/as profissionais da rede pública municipal de ensino de Uberlândia para refletirmos sobre o ano letivo/escolar de 2015; 2014. Disponível em:<cemepe.ntecemepe.com>. Acesso em: 10 dez.2016.

Data de recebimento: 18/07/2017

Data de aceite: 29/09/2017 